\title{
Combining eight research areas to foster the uptake of ecosystem-based management in fresh waters
}

\author{
Simone D. Langhans ${ }^{1,2,3}$ (D) | Sami Domisch ${ }^{1}$ | Stefano Balbi ${ }^{3}$ (i) | Gonzalo Delacámara ${ }^{4}$ | \\ Virgilio Hermoso ${ }^{1,5}$ (D) | Mathias Kuemmerlen ${ }^{6}$ (D) | Romina Martin ${ }^{7}$ । \\ Javier Martínez-López ${ }^{3}$ (D) | Peter Vermeiren ${ }^{6}$ (D) | Ferdinando Villa ${ }^{3}$ (D) | Sonja C. Jähnig ${ }^{1}$
}

${ }^{1}$ Leibniz-Institute of Freshwater Ecology and Inland Fisheries, Berlin, Germany

${ }^{2}$ University of Otago, Dunedin, New Zealand

${ }^{3}$ BC3-Basque Centre for Climate Change, Leioa, Spain

${ }^{4}$ IMDEA Water Institute, Madrid, Spain

${ }^{5}$ Centre Tecnològic Forestal de Catalunya (CEMFOR - CTFC), Solsona, Spain

${ }^{6}$ Eawag: Swiss Federal Institute of Aquatic Science and Technology, Dübendorf, Switzerland

${ }^{7}$ Stockholm Resilience Centre, Stockholm, Sweden

Correspondence

Simone D. Langhans, Department of Zoology, University of Otago, 340 Great King Street, Dunedin 9016, New Zealand.

Email: simone.langhans@otago.ac.nz

Funding information

German Federal Ministry of Education and

Research, Grant/Award Number: 01 LN1320A; Horizon 2020 Framework Programme, Grant/Award Number: 642317; Marie Sklodowska-Curie Global Fellowship, Grant/Award Number: 748625; Ramón y Cajal, Grant/Award Number: RYC-2013-13979

\section{Abstract}

1. Freshwater ecosystems are under a constant risk of being irreversibly damaged by human pressures that threaten their biodiversity, the sustainability of ecosystem services (ESs), and human well-being. Despite the implementation of various environmental regulations, the challenges of safeguarding freshwater assets have so far not been tackled successfully.

2. A promising way forward to stop the loss of freshwater biodiversity and to sustain freshwater-based ESs is by implementing ecosystem-based management (EBM), an environmental planning and adaptive management approach that jointly considers social and ecological needs. Responsible for considerable recent success in sustainably managing and conserving marine ecosystems, EBM has not yet been championed for fresh waters.

3. A major reason for the delayed uptake of EBM in fresh waters is likely to be its complexity, requiring planners to be familiar with the latest developments in a range of different research areas. EBM would therefore benefit from becoming more tangible to receive attention on the ground.

4. To facilitate uptake, eight core research areas for EBM and their innovations are introduced, and the way in which they feed into the workflow that guides the EBM planning stage is explained.

5. The workflow links biodiversity distributions with ES supply-and-demand modelling and SMART (specific, measurable, attainable, relevant, and timely) target planning, including scenario- and cross-realm perspectives, the prioritization of management alternatives, spatial prioritization of biodiversity conservation and ES areas, and the quantification of uncertainties. Given the extensive resources, time, and technical capacity required to implement the full workflow, a light and an ultralight version of the workflow are also provided.

6. Applied in concert, the eight well-known research areas allow for better planning and operationalizing, and eventually for implementing EBM in freshwater ecosystems. EBM has great potential to increase public acceptance by introducing the consideration of human needs and aspirations into typically biodiversity-driven conservation and management approaches. This will ultimately improve the integrity of freshwater ecosystems. 


\section{KEYWORDS}

biodiversity, catchment, ecosystem approach, ecosystem services, river

\section{1 | INTRODUCTION}

Freshwater ecosystems contain a diverse array of species and habitats that provide numerous societal benefits. Such ecosystems have been, and still are, under a constant risk of being irreversibly damaged by human demands and pressures, threatening the sustainability of freshwater ecosystems, their biodiversity, the provision of ecosystem services (ESs) and, ultimately, human health and well-being (Bennett et al., 2015). Despite a plethora of environmental directives, regulations, and action taken at regional and global levels, such as the Water Framework Directive (WFD; Council of the European Communities, 2000), the Birds Directive (Council of the European Communities, 2009), and the Habitats Directive (Council of the European Communities, 1992) in Europe, or the global Strategic Plan for Biodiversity 2011-2020 (Convention on Biological Diversity, 2010), which have led to some progress, anthropogenic risks have not yet been tackled satisfactorily (Secretariat of the Convention on Biological Diversity, 2014).

A potential way forward to become more successful in managing freshwater ecosystems towards reaching freshwater-bound targets is through ecosystem-based management (EBM). There is no single agreed definition of EBM (also referred to as the 'Ecosystem Approach'), but it can generally be understood as a collaborative management approach intended to restore, enhance, and protect the resilience of an ecosystem so as to sustain or improve ESs and conserve biodiversity, while considering human society as an integral part of that ecosystem (Long, Charles, \& Stephenson, 2015). Hence, EBM extends integrated approaches that have been applied to fresh waters in the past, such as Integrated Water Resource Management or Integrated River Basin Management. These management approaches focus on the uses and needs for water, and the management of water as a resource, through demand management, pricing, water conservation measures, and infrastructure (Juffe-Bignoli et al., 2016).

EBM has received considerable attention in the marine realm, where it has been used to develop sustainable fishery strategies, leading to a range of successful management examples (Wondolleck \& Yaffee, 2017). Despite demonstrable successes in marine management, EBM has not yet been championed in fresh waters. Their management, however, entails similarly complex and often intertwined interactions between social and ecological factors. Therefore, EBM is likely to be useful in improving freshwater management, for example, for the development of the WFD's river basin management plans. (Vlachopoulou et al., 2014).

Owing to the inherent complexity of ecosystems, and of fresh waters in particular, the management of fresh waters is rarely simple or comes with single solutions. Hence, challenges are expected regardless of the approach taken (Waylen et al., 2014). EBM, in particular, has been criticized as being too complex to be applied effectively (Ansong, Gissi, \& Calado, 2017). Inarguably, with its multidisciplinarity, EBM challenges researchers and planners alike. Those involved have to be familiar with the latest developments in multiple research areas, because science has to acknowledge critical societal challenges, and management can only be effective if it is evidence-based.

Thus, this article aims to strengthen links between EBM theory and practice in order to foster EBM implementation in freshwater ecosystems, and thereby to facilitate the conservation of freshwater biodiversity. To do so, the current status and recent innovations of eight core research areas of EBM are reviewed. The novelty of this article lies in the explanation of how these eight well-known research areas can be combined into a workflow to support EBM planning that is based on knowledge and collaboration. As the workflow may require substantial data and resourcing, two less complex versions of the workflow are also provided. Although the focus of this article is on fresh waters - highlighting the untapped potential of EBM in this realm - the workflow is transferrable to other ecosystems.

\section{2 | PLANNING EBM}

Several components are important when planning EBM. They comprise biodiversity, ESs, external scenarios (i.e. environmental scenarios that consider temporal changes such as socio-economic or governance developments), deficit identification, management strategies, and spatial planning (Figure 1), which link in the following way: two sets of mapped occurrence layers - one for biodiversity and one for ES delivery and demand - are the basis of an EBM plan. The choice of biodiversity and ESs depends on the respective freshwater system and the management objective in question. Distributions of these layers are projected into the future based on the external scenarios. The projected distributions are compared with the predefined targets to identify the deficits to be accounted for. Knowing the deficits helps to develop potential strategies to manage the system. Predictive models for biodiversity and ES distributions are then used to display the projected consequences of the different management strategies, which allows for prioritizing the strategy that is most beneficial for biodiversity conservation and ES provision. Projected biodiversity and ES distributions under the optimal management strategy are then used as input layers to optimize biodiversity conservation and ES delivery areas spatially within the system to be managed. The outcome of the spatial optimization is a plan that informs EBM implementation.

In addition to the components that build the EBM plan, several principles are crucial for the development of an effective EBM plan: (i) Biodiversity and ES distributions are modelled across aquatic and terrestrial realms, considering connectivity between adjacent ecosystems; (ii) external scenarios as well as management strategies are planned together with stakeholders; (iii) targets are defined based on environmental regulations, policy recommendations, and stakeholder preferences; (iv) an optimal management scenario is identified based on different criteria (including efficiency and equity, and the evaluation of predicted effectiveness of the outcomes); and ( $v$ ) uncertainties are quantified for biodiversity and ES models, stakeholder preferences, 
FIGURE 1 The conceptual framework for the planning stage of ecosystem-based management (EBM) consists of different components. Each component is informed by one or several research areas (indicated by the icons on the right of the figure). To perform a full cycle of EBM, the EBM planning stage, which is described in detail in this study, is followed by the implementation of the EBM strategy, and the monitoring and evaluation of respective outcomes. New knowledge, which is gained through the implementation and evaluation of the EBM strategy, feeds back into the different components, allowing an adaptive process. Detailed information on how to approach the EBM process that follows the planning stage is described by the 'Open standards for the practice of conservation' (http://cmp-openstandards.org/)

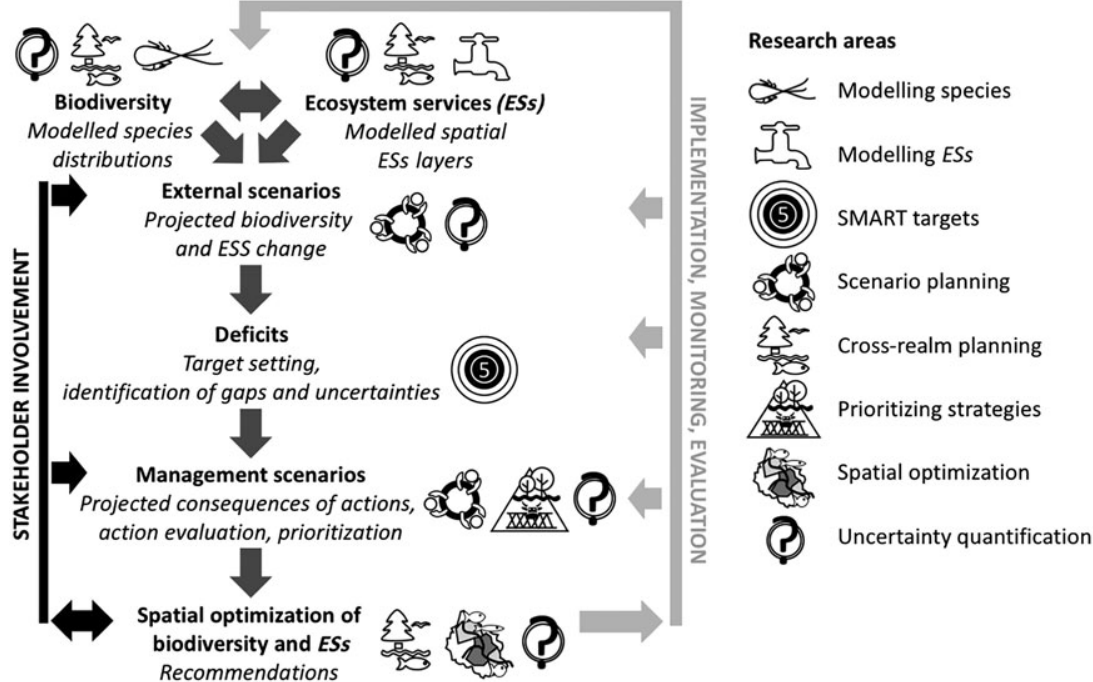

Recommendations and for predictions of management strategies, and these are reported to the decision makers together with the EBM plan (Figure 1). The second and third principles ensure conformity to national and international directives and enable community involvement.

Based on the EBM concept shown in Figure 1, eight research areas were identified that provide the knowledge necessary to put the planning stage of an EBM process into practice. The importance of the eight areas was supported by the fact that each of them has the potential to integrate multiple EBM key principles (Long et al., 2015) (Table 1). The following sections review these eight research areas in light of how their latest innovations can be used to benefit freshwater EBM planning.

\section{3 | THE EIGHT RESEARCH AREAS AND THEIR INNOVATIONS FOR FRESHWATER EBM}

\section{1 | Modelling species distributions}

Mapping species distributions (or a comparable taxonomic or functional unit) is a key aspect in any spatial planning procedure that accounts for patterns in biodiversity and constituent elements. Such patterns are often derived from observational occurrence data or from expert knowledge. Owing to the Wallacean shortfall, however, i.e. the challenge of precisely delineating the distribution of species, the true

TABLE 1 The 15 ecosystem-based management (EBM) key principles, listed by decreasing importance (1-15), according to the literature (Long et al., 2015). Their coverage by the eight research areas (icons are the same as used in Figure 1) is indicated with check marks. Principles 2 , 10, and 14 are not covered, as they are not part of the planning stage of EBM

Research areas

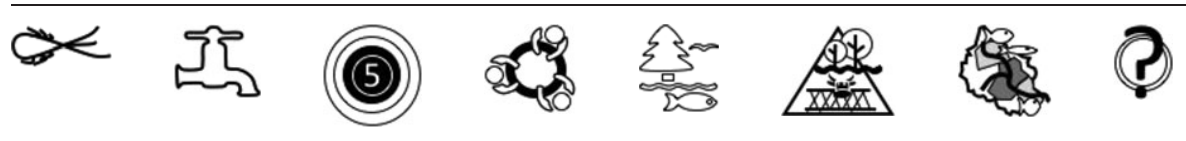

EBM key principles

$\checkmark \quad \checkmark$

$\checkmark$

$\checkmark$

Acknowledge uncertain

Interdisciplinary

Distinct boundaries

Decision reflects societal choice

Recognize coupled social-ecological system

Ecological integrity and biodiversity

Account for dynamic nature of ecosystems

$\begin{array}{lll}2 & -10 \\ \checkmark & 2\end{array}$

$\checkmark$

Sustainability

$\checkmark$

Integrated management

Stakeholder involvement

Use of scientific knowledge

Appropriate spatial and temporal scales

$\begin{array}{lll}2 & -1 \\ 2 & 2 \\ 2 & 2\end{array}$

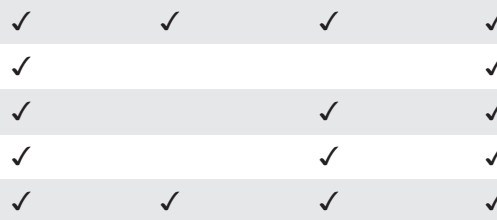

Adaptive management

Consider ecosystem connection

$\begin{array}{ll}2 & \\ 2 & 2 \\ 2 & 2\end{array}$

$\begin{array}{lll}2 & -1 \\ \checkmark & \checkmark\end{array}$

$\checkmark$

$\checkmark$

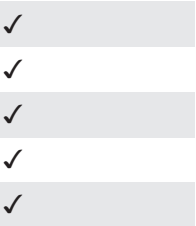

$\checkmark$

$\begin{array}{lllll}\checkmark & & \checkmark & \checkmark & \checkmark \\ \checkmark & \checkmark & \checkmark & \checkmark\end{array}$


distribution range of any species can at best be simulated (Bini, Diniz, Rangel, Bastos, \& Pinto, 2006). Such simulations are possible using species distribution models (SDMs). SDMs have been widely used in ecology to quantify how environmental and anthropogenic factors affect species distributions (Booth, Nix, Busby, \& Hutchinson, 2014), and have increasingly been used to predict patterns in species distributions under changing environmental conditions. For example, using SDMs Kuemmerlen et al. (2015) found that future land-use change has a stronger negative impact on the benthic invertebrate community of the Changjian catchment (south-east China) compared with climate change, whereas the effects of climate and land-use change counterbalance each other to a certain degree. Consequently, when appropriately used, SDMs can provide the spatially extensive biodiversity information upon which EBM is based.

Current innovations in SDMs that benefit EBM planning are twofold. First, the increasing diversity, availability, and quality of input data provides many new opportunities. Nonetheless, there is still a paucity of continuous and widespread environmental data providing accurate information on habitat properties at small spatial scales. This hinders the inclusion of highly relevant parameters such as discharge, flow velocity, water temperature and depth, among others, in current freshwater SDMs (Domisch, Amatulli, \& Jetz, 2015). Second, SDM methods are continuously improving - for example, by considering the network structure of rivers affecting how connectivity is spatially implemented (Peterson \& Hoef, 2010). The addition of temporally dynamic features provides a promising future direction in improving the outputs of static correlative SDMs. Static correlative SDMs are not dynamic per se, but distributions can be predicted for several time slices to mimic the dynamic pattern of the models, as has been done within the terrestrial realm (e.g. daily for migratory birds (Fink et al., 2010), or across decades (Hayes, Cryan, \& Wunder, 2015). Further improvements in this area would be highly relevant for predicting species distributions over time (Martínez-López, Martínez-Fernández, Naimi, Carreño, \& Esteve, 2015).

Improvements to addressing the uncertainty of SDM outputs include their correction for biotic interactions, which are at present only implicitly incorporated (models and parameter inference are based on current observational data that inherently include the effects of biotic interactions), the integration of species movement, dispersal, and history, and the effects of genetic differentiation (Qi et al., 2018). For example, Gavish et al. (2017) showed for the benthic invertebrate community from the Kinzig catchment (central Germany) that, in certain cases, SDMs that incorporate surrogates for biotic interactions increase the predictive performance at the species and community levels. Hence, the continued development of SDMs will provide further opportunities for their successful uptake in EBM frameworks.

\subsection{Modelling ecosystem services supply and demand}

Inherent to any EBM is the importance of ecosystems to human wellbeing and the tendency of social systems to modify ecosystems. These two relationships are connected through complex adaptive processes, which shape both the supply and the demand of ESs. Hence, to assess
ES distributions, models should represent supply and demand (i.e. providers and beneficiaries of ESs) in order to display the natural and social features between which ESs can flow. Beneficiaries are the social agents that benefit from the ecological processes sustained by providers. Assessing ES dynamics with explicit consideration of both natural and human components enables the quantification of flows between providers and beneficiaries. As the same variables and subjects can simultaneously participate (in different roles) for different ESs, scenarios can be built where the change of any variable affects all other linked components. This allows the quantification of important trade-offs among different ESs. Such trade-offs could include: hydropower generation versus connectivity of fish habitats, groundwater extraction for agriculture versus maintenance of wetlands and associated biodiversity, water transfers among different catchments versus maintaining minimum ecological flows, natural wetlands as green infrastructures that process nutrients versus using them as recreational areas, among others (Villa, Portela, Onofri, Nunes, \& Lange, 2015).

At present, the majority of ES assessments yield static snapshots depicting proxy values, usually computed on the basis of look-up tables, in which the main input is land-cover type (Ricaurte et al., 2017). A static snapshot, for example, would be to assign fixed parameters such as water retention capacity to a certain land-cover type without considering the seasonal supply and demand of water within that catchment. Such assessments disregard the dynamic nature of ESs as assets of coupled social-ecological systems that exhibit complex feedback mechanisms. Hence, although used as a typical ES mapping shortcut, this approach does not necessarily correspond to a realistic and credible representation of the dynamics of a system. This can be problematic, especially for ecosystems that are less well represented by proxy land use values, as is the case for fresh waters. Context-specific models that consider social-ecological processes and their linkages with specific services relevant in time and space, should lead to more holistic assessments (Garcia-Prats, del Campo, \& Pulido-Velazquez, 2016; Martínez-Fernández et al., 2014; Nassl \& Löffler, 2015).

To improve ES models in the future and thereby ensure successful EBM, a better understanding is needed of how biodiversity and ecosystem processes are linked to each other and their ESs, as well as how changes in the condition of fresh waters affects the delivery of ESs. On the demand side, it is still quite unclear how individual and collective decisions are influenced by environmental changes and how society responds to changes in the supply of freshwater ESs.

\section{3 | Planning with SMART targets}

Traditionally, directives and policies relevant for fresh waters (e.g. the WFD and the Habitats Directive) strove to protect selected species, habitats, or environmental conditions. Consequently, they use targets developed for single-sector management, i.e. for fresh waters. Hence, the current challenge for freshwater EBM lies in defining SMART targets, i.e. targets for objectives that define the quantity of a component of the social-ecological system to be reached or conserved, and are specific $(S)$, measurable $(M)$, achievable $(A)$, relevant (realistic) $(R)$, and timely $(\mathrm{T})$. 
Using SMART principles for target setting gained attention when the Convention on Biological Diversity (CBD) developed 20 SMART Aichi targets (Perrings et al., 2010). Whether target 11, which is of particular relevance for fresh waters and relates to the implementation of protected areas and 'other effective area-based conservation measures', will be fully reached by 2020 remains questionable (Juffe-Bignoli et al., 2016). At present, the target still lacks quantifiable definitions of success (besides the extent of the protected area) to evaluate effective, equitable biodiversity management, the ecological representation of a mix of ecosystems, and the connectivity between sites to allow species dispersal (Tittensor et al., 2014). Hence, indicators and current baselines for these targets have to be established to be able to quantify the distance to the defined endpoints (Juffe-Bignoli et al., 2016).

As EBM becomes more popular, targets and respective indicators are needed for entire coupled social-ecological (freshwater) systems (Levin, Williams, Rehr, Norman, \& Harvey, 2015). EBM targets have to reflect the freshwater values that society attaches to the respective fresh water, along with targets underpinned by regulations that consider the ecology of the system. Developing such targets is complex. For example, anglers may want an invasive fish species to be present in a lake, whereas a freshwater regulation will require its eradication. Hence, target setting is best informed by predictions of the consequences of management actions, and how they propagate through the respective social-ecological system.

Quantifying societal preferences is an additional challenge in EBM target setting. Participatory decision-making processes, such as those provided by Multi-Criteria Decision Analysis (Eisenführ, Weber, \& Langer, 2010), can help to structure the process. Reichert, Langhans, Lienert, and Schuwirth (2015) describe how societal preferences can be elicited and included in the decision-making process together with scientific knowledge. Nevertheless, whether a collaborative process will be successful largely depends on the willingness of the involved parties to contribute towards jointly negotiated solutions (Bodin, 2017).

\subsection{Planning with scenarios}

Scenario assessment makes use of alternative data inputs, model simulations, and narratives. In EBM the use of scenarios provides stakeholders and institutions with the outcomes of their current decisions and supports collective decision-making through comparing and assessing alternative courses of action. Depending on the need, the use of scenarios can support exploratory, normative, or predictive planning analyses (Oteros-Rozas et al., 2015).

During the EBM planning stage, scenarios can help in several ways, by defining boundary conditions that are not captured dynamically in models. For example, a model that predicts the consequences of river restoration actions based on trade-offs between ecological and social objectives may not explicitly consider economic trends. Nonetheless, the availability of funds will influence management outcomes considerably. Such information can be part of the scenario narrative. Scenarios can also help to reduce uncertainty by testing different spots or trajectories of the uncertain space. To do so, a scenario could be designed taking into account the lower end of a process interval, while at the same time an alternative scenario is designed to capture the upper end of the same process. Scenarios of stream flow based on climate forecasts to predict changes in the size or the frequency of future floods is an example of such an approach. Scenarios can also account for changes that are, in principle, unknown, with the dispersal capacities of many species under climate change being examples of this. Markovic et al. (2014) dealt with this challenge by assuming two dispersal scenarios when modelling the distribution of freshwater plants, fishes, molluscs, odonates, amphibians, crayfish, and turtles across Europe: an optimistic scenario, assuming free dispersal to suitable catchments, and a pessimistic scenario, assuming no dispersal at all. Although the reality probably falls somewhere between those two scenarios, they are useful for representing two extremes of a continuum of possible outcomes (Franklin, Wejnert, Hathaway, Rochester, \& Fisher, 2009).

A current challenge for the use of scenarios in EBM planning is that they should address the spatial and temporal scales relevant for management and for the dynamics of the modelled system. The temporal scale of processes in social-ecological systems can vary considerably. For example, when long-term management actions are envisaged, it might be better to develop a series of shorter-term scenarios to reduce uncertainty and allow for further refinement of processes. Such an approach is appropriate when dealing with species dispersal that might occur rapidly at the onset of an implemented management strategy, but may slow down later (Winking, Lorenz, Sures, \& Hering, 2016). On the other hand, climate and biodiversity scenarios are often limited to large-scale environmental changes, of mainly global or national scale. Hence, they are not well connected to local decision-making, and vice versa (Rosa et al., 2017).

A new generation of multiscale scenarios that capture the whole coupled social-ecological system seems to hold promise for EBM planning. Such scenarios not only describe environmental change, but also model how stakeholders may respond to changes in drivers, biodiversity, ESs, and human well-being (Rosa et al., 2017). To develop such scenarios, better knowledge of the links between ecosystems and human well-being is needed. Making a first step in this direction, Venohr et al. (2018) have suggested how ecological quality, recreational quality, and management can be conceptually linked in fresh waters.

\section{5 | Planning across realms}

Spatial connectivity has long been acknowledged as pivotal in maintaining natural ecological processes and biodiversity in fresh waters (Pringle, 2001). Hence, there are many concepts and analytical management tools to manage connectivity within catchments. Longitudinal connectivity, for example, has been integrated in catchment management approaches to allocate priority conservation areas. Hermoso, Linke, Prenda, and Possingham (2011) tested the effect of connectivity in spatial optimization analyses, and found that the inclusion of connectivity resulted in whole sub-basins being prioritized as fish conservation areas, rather than river corridors alone. Subsequently, longitudinal connectivity has been commonly considered in freshwater conservation planning, and to inform management (Langhans, Gessner, Hermoso, \& Wolter, 2016). Similarly, lateral connectivity between various freshwater habitats, such as lakes and 
wetlands that are not necessarily directly connected along the river network, has also been considered (Hermoso, Kennard, \& Linke, 2012).

Meeting objectives in freshwater systems alone can compromise the achievement of objectives in other, linked realms, which may lead to substantial trade-offs (Rieman, Hessburg, Luce, \& Dare, 2010). By contrast, planning management actions across connected ecosystems can result in co-benefits, if the management achieves objectives in several of the ecosystems (Adams et al., 2014). Although guidelines for freshwater management highlight the need for integration, there are only a few cross-realm case studies to date that target freshwater-terrestrial (Leonard, Baldwin, \& Hanks, 2017) or terrestrial (catchment)-marine systems (Klein et al., 2010). Some studies claim to integrate management or conservation across realms, but they only consider some forms of influence: for example, a threat originating in one realm and how it affects connected realms (Álvarez-Romero et al., 2015). One of the cross-realm management plans that has been applied (for the Gulf of California) aimed to identify areas in river catchments for protection or management, specifically to conserve terrestrial biodiversity and, concurrently, maintain coastal-marine water quality downstream (Álvarez-Romero, Pressey, Ban, \& Brodie, 2015).

Despite progress made in the theory of cross-realm planning, more knowledge is necessary to better understand the co-benefits and tradeoffs across realms, and how socio-economic interactions can be integrated into planning (Álvarez-Romero, Adams, et al., 2015). In the future, more on-the-ground applications are needed to demonstrate the theoretical advancements and to provide practical guidance.

\subsection{Evaluating and prioritizing management strategies}

Historically, environmental water management focused on effectiveness (i.e. the impact of management on ecological outcomes) and efficiency (i.e. the benefit-to-cost ratio). Hence, there is ample guidance (e.g. concepts, protocols, indicators, and metrics) on how best to achieve ecological targets (Revenga, Campbell, Abell, De Villiers, \& Bryer, 2005; Woolsey et al., 2007).

The most commonly used approach to maximize efficiency in environmental management is the analysis of cost-effectiveness. Cost-effectiveness is the degree to which a management strategy is effective in relation to the overall costs, including opportunity costs (Naidoo \& Adamowicz, 2006), when implementing the action needed to reach the anticipated outcome. Cost-effectiveness analyses ensure that the cheapest (i.e. lowest-cost) solution for reaching predefined targets is identified, whereas an additional incremental cost analysis reveals how costs increase with increasing target levels - information that can considerably facilitate decision-making. Including information on the spatial heterogeneity of conservation or management costs as an input variable to the planning process has been shown to be beneficial for reaching targets at lower costs. For example, Ferraro (2003) found that the costs for managing a river catchment in upstate New York to preserve drinking water quality downstream could be considerably reduced when costs (i.e. the acquisition costs of land parcels that contain riparian buffer) and benefits (i.e. the reduction in pollutants and sediments) were considered concurrently, instead of the benefits alone. In contrast to such monetary costs, Linke et al. (2012) used a cost surrogate (i.e. a landscape measure of catchment disturbance) to prioritize the least disturbed conservation areas for fish in the Daly River catchment (Northern Australia). It is therefore just as, or even more, important to consider costs in freshwater EBM planning (Carwardine et al., 2008).

Recently, a third criterion - social equity - has gained importance in management assessments (Zafra-Calvo et al., 2017): e.g. the CBD Aichi target 11 asks for $17 \%$ of inland water to be conserved through effectively and equitably managed systems of protected areas. Social equity refers to fair or just treatment of individuals or groups (Law et al., 2018), and consists of four dimensions (McDermott, Mahanty, \& Schreckenberg, 2013): procedure (equal involvement), distribution (of costs, benefits, rights, responsibilities, risks, etc.), recognition (respecting knowledge systems, values, social norms, etc.), and context (social, environmental, economic, and political history and circumstances). A recent systematic review analysed 139 peer-reviewed studies and found that the majority of conservation actions have negative equity outcomes (Friedman et al., 2018). Hence, we recommend accounting for procedural, recognitional, and contextual dimensions directly during the EBM planning stage. Procedural equity can be addressed either when selecting stakeholders or when collaboratively identifying objectives and targets. Distributional equity strongly depends on the choice of management strategy. For example, the morphological rehabilitation of a channelized river reach imposes costs for the local taxpayers, whereas improved water quality or flood protection benefits downstream communities. Therefore, the equitable distribution of costs and benefits should be considered as one of the criteria in assessing and prioritizing management strategies. Future projects on the ground that include equity as a criterion will provide much-needed experience on how to assess specifically the different equity dimensions, and on how they influence the success of a freshwater management strategy.

\section{7 | Spatial planning for biodiversity conservation and ecosystem services}

The concept of protected areas is currently moving from being almost exclusively driven by biodiversity conservation towards including separate management zones, where additional values, such as ESs, must be restored and conserved (Hermoso, Abell, Linke, \& Boon, 2016). There is agreement on the benefits of integrating ESs into local and regional landscape planning (Tallis \& Polasky, 2009). For example, the CBD Aichi strategic goal $D$ is to 'enhance the benefits to all from biodiversity and ESs'. This strategy is increasingly being viewed as necessary to safeguard the critical services that humans receive from biodiversity and ecosystems, but also because it provides an opportunity to find new resources and obtain support from the public for protected areas and conservation (Harrison et al., 2016).

Integrating the planning of ESs and freshwater biodiversity is challenging, because securing access to some services might threaten other services or biodiversity directly (Hermoso, Cattarino, Linke, \& Kennard, 2018). For example, granting access to fresh water or releasing the hydropower capacity of a river reach might have impacts not 
only on biodiversity, but also on the recreation potential within that reach or on water purification. On the other hand, there are opportunities to enhance co-benefits between biodiversity and the maintenance of ESs that are more compatible with conservation (Atkinson et al., 2016). For example, protecting and maintaining riparian forest increases carbon storage and flood control, while concurrently benefitting riparian and freshwater biodiversity (Bryan et al., 2016).

To ensure that the application of the planning methods is flexible enough in practice and identifies portions of ecosystems that are feasible for management, Abell, Allan, and Lehner (2007) proposed a multi-zone approach that organizes the landscape/riverscape into different management zones under different management regimes. Hermoso, Cattarino, Kennard, Watts, and Linke (2015) tested this approach for the purpose of protecting freshwater fish in the Daly River (northern Australia), i.e. first without considering any ESs to test the efficiency of the approach. Using three different zones (core conservation zones that are connected through critical management zones, buffered upstream by catchment management zones), they found that multi-zonal conservation plans were significantly more efficient. More specifically, the total area in need of strict conservation was reduced by twofold, compared with a single-zone approach. In the follow-up study (Hermoso et al., 2018), they extended the goal of the conservation planning exercise not only to identify priority areas for the conservation of freshwater fish, turtles, and waterbirds in the Daly River, but concurrently for the provision of four freshwater ESs. Two of these ESs - flood regulation by riparian forests and the provision of perennial water - were deemed to be compatible with conservation goals, whereas groundwater provision for agriculture and recreational fisheries were deemed less so. By applying three conservation zones (for biodiversity and compatible ESs) and two production zones (for incompatible ESs), conservation plans achieved up to $53 \%$ more co-benefits for low ESs targets, compared with a single-zone approach. In addition, incompatible ESs were represented $56 \%$ less often within conservation zones when ES targets were set high.

Hence, systematic multi-zone plans can help to unlock the potential of conservation recommendations for freshwater ecosystems by enhancing the efficiency of a conservation plan. Now, more implementations of such plans are needed to further fine-tune the approach.

\section{8 | Quantifying uncertainties}

Owing to the lack of a comprehensive understanding of the structure, functioning, and dynamics of freshwater ecosystems in the face of rapid environmental changes, management decisions tend to be based on uncertain knowledge. This is further complicated by uncertainties in stakeholder preferences, uncertainty regarding the predictions of the consequences of management actions, uncertainty around feedback and stochasticity within the socio-ecological system, and the intrinsic uncertainty of predicting future states. Consequently, uncertainty assessments and the documentation of uncertainty are particularly important in the context of EBM. For example, the quantified uncertainty of the degree to which a management strategy will fulfil its objectives is important information for prioritizing strategies (Reichert \& Borsuk, 2005). The full spectrum of uncertainty, however, is rarely accounted for in environmental management because it is impossible to do so. Thus, to be successful, EBM requires an iterative process of evaluation and learning in the form of adaptive management coupled with the quantification of uncertainty. Indeed, successful EBM relies heavily on a transparent assessment of the quality and reliability of each of its components (Clark et al., 2001).

Advances in quantifying uncertainty have recently been made in environmental modelling (Guisan \& Zimmermann, 2000). The main sources of uncertainty in models are those relating to model inputs, model structure (i.e. process uncertainty), and model parameters (Knutti, 2008). Model inputs in the form of ecological measurements almost always have large measurement errors and data limitations. Taking advantage of citizen-science programmes, the increasing availability of automated measuring technologies, as well as qualitycontrol procedures can greatly improve data quality and quantity, and reduce input uncertainty (Harmel, Cooper, Slade, Haney, \& Arnold, 2006; Vermeiren, Munoz, Zimmer, \& Sheaves, 2016). For example, Creek Watch pairs citizen scientists with smartphone applications to fill data gaps in freshwater monitoring and has been useful in improving water management practices (Kim, Robson, Zimmerman, Pierce, \& Haber, 2011). Uncertainty in model structure often results from incomplete knowledge of the system, from competing theories, and from the need to simplify model structure (Knutti, 2008). Models using artificial intelligence can overcome a lack of system understanding, but are often difficult for the average practitioner or policymaker to understand, and require large quantities of data to run (Lek \& Guegan, 1999); therefore, they are a challenge to apply in practice. Given the long history both of managing and studying fresh waters, uncertainty in model structure could be reduced with increased collaboration among scientists and managers. Parameter uncertainty also stems from incomplete system knowledge. The recently increased attention to Bayesian approaches can be useful in this context, as they formulate parameter distributions rather than single-point estimates of parameter values (Ellison, 2004). In addition, Bayesian inference uses prior knowledge to balance uncertainty in input data. Moreover, when combined with empirical data, Bayesian inference allows for the updating of current knowledge (Charniak, 1991), which fits well in an adaptive management context. Overall, we see a high potential for Bayesian techniques in EBM, especially with the increasing availability of computational power.

\section{4 | A WORKFLOW FOR OPERATIONALIZING EBM PLANNING}

Based on the innovations of the eight research areas and the concept of how they contribute to freshwater management (Figure 1), a workflow for operationalizing the EBM planning stage was developed. The complete workflow requires substantial data and resourcing. Hence, depending on the environmental problem, and the available data, resources, and time constraints, its application may not be 
feasible. In such situations, one of the two less complex versions of the workflow that are introduced below may be applied.

The complete workflow consists of nine steps (Figure 2), and starts with the two sets of distribution layers: one for biodiversity and one for ESs. SDMs are used to model the respective biodiversity distribution at time $t=0$ (Figure 2, step 1). SDMs use the occurrence records of species and the environmental conditions at those same locations to assess the species-environment relationship and project a range-wide, probabilistic habitat suitability index onto the study area (Elith \& Leathwick, 2009). SDMs can be based on a wide range of correlative to mechanistic algorithms (Guisan \& Zimmermann, 2000), and can be developed to produce either a single community index or predictions for individual species. The appropriate choice of modelling method needs to consider the requirements of the EBM plan and the available input data, existing knowledge on the freshwater system, the optimal level of model complexity, and the computational demand. Correlative models are often convenient, as they can handle the type of data that is most often available: opportunistic point records combined with environmental covariates. In addition, at large spatial and temporal scales where national or provincial management decisions are made, static correlative models can deliver an acceptable explanatory power, yielding informative results tailored to the scale and time frame of the EBM plan. Their reduced consideration of mechanistic understanding, however, could limit their power (Guisan \& Zimmermann, 2000). Mechanistic models also have limitations, most notably that they require more detailed data and knowledge of the system, often resulting in these models being applied at smaller spatial scales.

In parallel with step 1, ES models are developed. To do so, one of many different methodologies can be selected (for a comprehensive list and detailed description, see Domisch et al. 2017). One powerful software platform is ARIES (ARtificial Intelligence for Ecosystem Services), which integrates multiple modelling paradigms for the spatiotemporal modelling and mapping of ESs. The methodology uses artificial intelligence features such as semantics and machine learning for model selection and assembly to quantify ES flows from ecosystems to beneficiaries (Villa et al., 2014). Another commonly used software package is INVEST (Integrated Valuation of Ecosystem Services and Tradeoffs), which also allows for the spatial mapping and modelling of multiple ESs. It includes a diverse set of provisioning, regulating, and cultural services from marine and terrestrial environments. The models primarily provide results in biophysical terms to which valuations can be applied (Sharp et al., 2018).

After having established the models for biodiversity and ESs, experts select and combine external scenarios, ideally together with stakeholders (step 2). The scenarios must consider spatial and temporal scales that are relevant for the management targets and for the dynamics of the modelled system. The scenarios used in the model analysis need to be defined (i.e. explorative, normative, or descriptive) and justified. If the goal is to learn more about uncertain processes and to explore risks, it is advisable to develop extreme scenarios for exploration and learning purposes. However, if the goal is to narrow down the environmental effects on the development of particular species, scenarios should be chosen that predict expected environmental changes accurately at species-relevant scales.

Environmental variables are projected according to the external scenarios, and then included in the statistical relationship to forecast species and ES distributions for each of the scenarios (step 3). Experts and stakeholders identify biodiversity and ES targets according to policies and subjective preferences. Additional socio-ecological targets

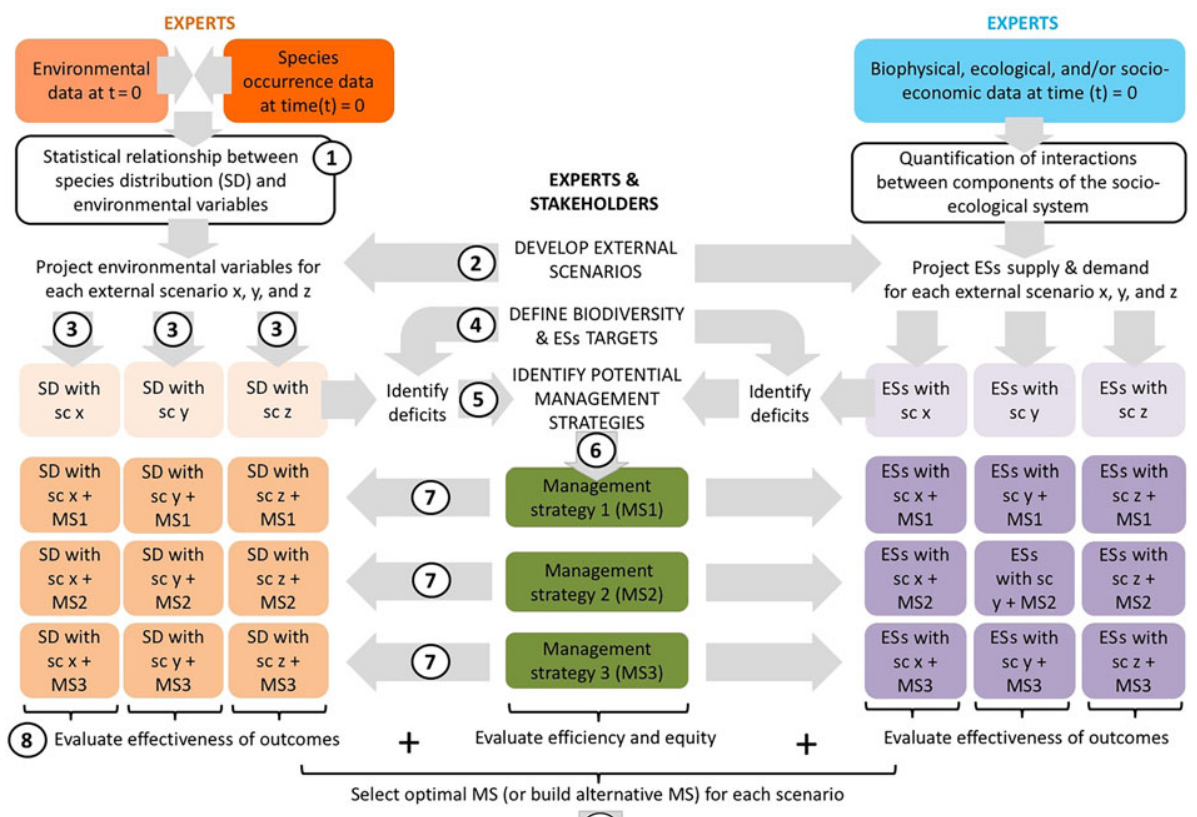

(9)

Spatial optimization of biodiversity and ESs management areas based on data predicted for the optimal MS (for each scenario)

FIGURE 2 The nine steps of the workflow that integrate the methodological advancements in the respective research areas. Executing the workflow helps to structure and operationalize the ecosystem-based management (EBM) planning stage and leads to the identification of a spatially optimized management plan 
that are particularly important to the community can also be included and quantified here (step 4). System deficits can now be identified for each scenario, by comparing projected species and ES distributions with the pre-defined targets (step 5).

With the deficits for biodiversity and ESs laid out, a set of potential management strategies that could reach the identified targets for biodiversity and ES objectives are developed, ideally in collaboration with stakeholders (step 6). Management strategies entail actions that, if implemented, will help meet the socio-ecological objectives and targets identified for the respective system. To compare the effect of different management strategies, baseline (i.e. 'business as usual') scenarios are first used to predict the future state of a freshwater system given external scenarios and current management practices. The strength of the analyses of baseline scenarios is to identify deficits and, hence, the key challenges that are translated into management objectives. The management strategies entail alternative management actions to achieve these management objectives, which allows predicting the consequences of the different strategies for biodiversity and ESs under the different external scenarios (step 7). Comparing the assessments of the predicted consequences of different management strategies, based on effectiveness, efficiency, and social equity, will enhance the understanding of leverage points and will show uncertainties. This, in turn, will ultimately aid in the identification of the most robust strategy. Stakeholder involvement is crucial in the development of management strategies to ensure realism and acceptance for further implementation (Talley, Schneider, \& Lindquist, 2016) (step 8).

Spatially explicit biodiversity and data on ESs, predicted from the optimal management scenario, are used for the spatial planning of the EBM following the principles of systematic conservation planning (step 9). A range of different software, widely used in conservation planning, has begun to be applied to planning processes, such as holistic management planning. These plans go beyond biodiversity conservation and try to integrate other objectives such as the use of natural resources (Levin et al., 2013). The software packages optimize the spatial allocation of biodiversity conservation and ES delivery areas across the respective area to be managed (optimally across freshwater, coastal, and marine zones), while minimizing cost and maximizing targets for the management plan (Hermoso et al., 2018). Two examples of planning software are MARXAN WITH ZONES (Watts et al., 2009) and GUROBI (Beyer, Dujardin, Watts, \& Possingham, 2016). MARXAN WITH ZONES (Watts et al., 2009) is an extension of MARXAN (Ball, Possingham, \& Watts, 2009), which is currently the most used planning software worldwide. MARXAN WITH ZONES allows the planner to specify different management zones, each of which can be characterized by actions, objectives, and restraints. One zone is usually the 'no-take' or 'conservation only' zone, whereas other zones allow the use of ESs. Besides optimizing costs, the software can be used to emphasize specific features of the management plan by giving different weights to different ESs or different costs to each management zone. In addition, irreplaceable areas that, for example, contain critically endangered species, or culturally significant values that should not be traded-off in the optimization, can be locked into the management plan. GUROBI uses the same input files as MARXAN, but is based on integer linear programming, which has been shown to outcompete traditional simulated annealing tools (as used in MARXAN) in both running time and accuracy (Beyer et al., 2016).

The products of step 9 are EBM plans that inform decision makers and stakeholders. The plans may need to be refined when new input data become available and recalculated until a plan has been agreed. Step 9 concludes the EBM planning stage (for the additional components needed to build a full EBM cycle, i.e. adaptive management, see Figure 1).

\section{5 | THE LIGHT AND ULTRALIGHT VERSIONS OF THE WORKFLOW}

The main difference between the full and the light version of the workflow is that the light workflow does not consider future trends, disregarding external scenarios (Figure 3). Hence, deficits are identified based on the present status of species and ES distributions, and potential management strategies are developed accordingly (see Barbosa et al., 2019 for an example application). The steps that follow remain the same as in the full workflow. Excluding external scenarios simplifies the workflow, as less stakeholder involvement is needed and fewer models have to be built. A disadvantage of the light version of the workflow is that it bases recommendations only on the present distributions of biodiversity and ESs. In the future, depending on the location of the system in question, these recommendations may become irrelevant when species and ESs are redistributed in response to climate change or other drivers (Pecl et al., 2017). In addition, the time interval between action planning, implementation, and observing a change in the managed system may be decades (Kail, Brabec, Poppe, \& Januschke, 2015). Hence, considering future distributions of biodiversity and ESs may be crucial for establishing a cost-effective management process and is therefore highly recommended.

Compared with the light version, the ultralight version does not consider external scenarios or potential management strategies (Figure 4). Similar to the light version, it is based on present biodiversity and ES distributions. However, instead of potential management strategies, stakeholders identify different management zones that they wish to be considered in the respective system (see Domisch et al. (2018) for an example application). Abell et al. (2007) proposed three potential zones: (1) the freshwater focal zone, which is dedicated to the protection of a specific freshwater feature; (2) the critical management zone, which needs to be managed in a way that ensures the functionality of the focal area; and (3) the catchment management zone, which contains the entire upstream catchment of a critical management zone (see above). The inclusion of management zones when spatially optimizing biodiversity and ES delivery areas allows accounting for trade-offs and co-benefits between biodiversity and different ESs. Hence, it helps diffuse concerns of disregarding essential ESs for the sake of biodiversity conservation. This version of the workflow may be the preferred option to apply when time and money are constrained, or if a management strategy has already been agreed. However, as for the light version, the ultralight approach cannot be used to develop recommendations for the future, and nor does it evaluate and rank different, alternative management strategies. 


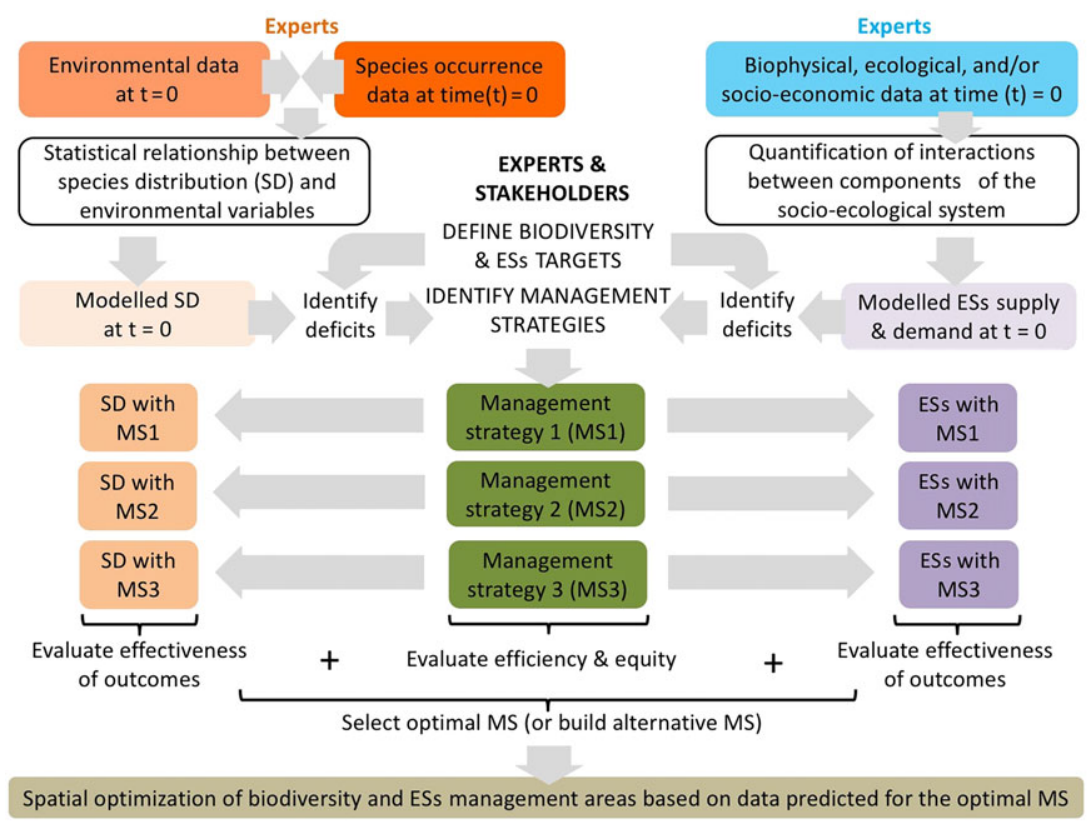

FIGURE 3 The less complex workflow (light version) is based on the current status of biodiversity and ecosystem services (ESs), considering different management strategies that are evaluated and ranked according to relevant criteria

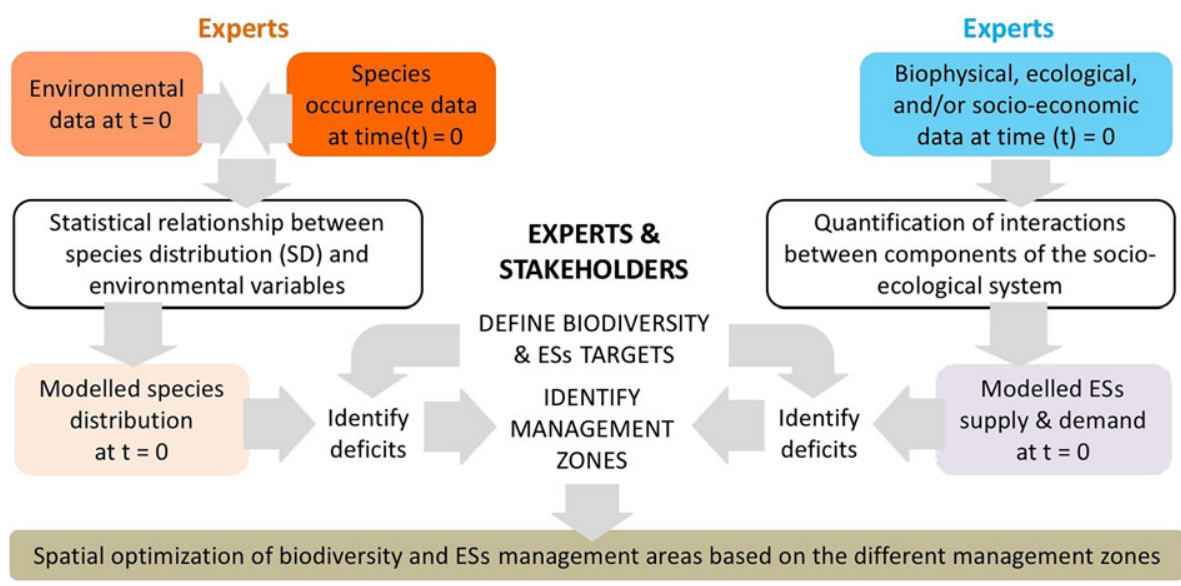

FIGURE 4 The least complex workflow (ultralight version) considers the present status of biodiversity and ecosystem services (ESs) and different management zones (sensu Abell et al., 2007)

\section{6 | SYNOPSIS}

The novelty of this study lies in the combination of eight well-known research areas that together allow better planning, operationalization, and eventually implementation of EBM in freshwater ecosystems. The proposed workflow helps to operationalize the EBM planning stage by considering the many different objectives freshwater management has, such as spatial optimization, cost efficiency, social equity, the achievement of conservation and ES targets, and the maintenance of irreplaceable biodiversity or cultural values. In addition, it facilitates integration between disciplines of knowledge at multiple spatial and temporal scales, and among policies. It is not intended to be a rigid blueprint. Instead, it is an iterative procedure that can be modified to account for new information and localized changes depending on the freshwater systems to be managed. The documented success of EBM in the marine realm leads us to believe that this study will provide the means to apply EBM in fresh waters, improve management effectiveness, and create socio-ecological benefits through involving local communities.

\section{ACKNOWLEDGEMENTS}

This research received funding from the European Union Horizon 2020 Research and Innovation Programme under grant agreement no. 642317. S.D.L. received additional funding from the European Union Horizon 2020 research and innovation programme under the Marie Skłodowska-Curie grant agreement no. 748625. SCJ was supported by the German Federal Ministry of Education and Research (BMBF) through the 'GLANCE' project (Global Change Effects in River Ecosystems; 01 LN1320A). V.H. was supported by a Ramón y Cajal contract funded by the Spanish Government (RYC-2013-13979). We thank Mark Schallenberg for proofreading, and Philip J. Boon, Diego Juffe-Bignoli, and two anonymous referees for helpful comments that significantly improved the article. 


\section{ORCID}

Simone D. Langhans (D) https://orcid.org/0000-0001-9581-3183

Stefano Balbi (D) https://orcid.org/0000-0001-8190-5968

Virgilio Hermoso (D) https://orcid.org/0000-0003-3205-5033

Mathias Kuemmerlen (D) https://orcid.org/0000-0003-1362-3701

Javier Martínez-López (D) https://orcid.org/0000-0002-0825-7252

Peter Vermeiren (D) https://orcid.org/0000-0003-3541-5946

Ferdinando Villa (D) https://orcid.org/0000-0002-5114-3007

Sonja C. Jähnig (10) https://orcid.org/0000-0002-6349-9561

\section{REFERENCES}

Abell, R., Allan, J. D., \& Lehner, B. (2007). Unlocking the potential of protected areas for freshwaters. Biological Conservation, 134, 48-63. https://doi.org/10.1016/j.biocon.2006.08.017

Adams, V. M., Alvarez-Romero, J. G., Carwardine, J., Cattarino, L., Hermoso, V., Kennard, M. J., ... Stoeckl, N. (2014). Planning across freshwater and terrestrial realms: Cobenefits and tradeoffs between conservation actions. Conservation Letters, 7, 425-440. https://doi. org/10.1111/conl.12080

Álvarez-Romero, J. G., Adams, V. M., Pressey, R. L., Douglas, M., Dale, A. P., Auge, A. A., ... Perdrisat, I. (2015). Integrated cross-realm planning: A decision-makers' perspective. Biological Conservation, 191, 799-808. https://doi.org/10.1016/j.biocon.2015.07.003

Álvarez-Romero, J. G., Pressey, R. L., Ban, N. C., \& Brodie, J. (2015). Advancing land-sea conservation planning: Integrating modelling of catchments, land-use change, and river plumes to prioritise catchment management and protection. PLoS ONE, 10, e0145574. https://doi. org/10.1371/journal.pone.0145574

Ansong, J., Gissi, E., \& Calado, H. (2017). An approach to ecosystembased management in maritime spatial planning process. Ocean and Coastal Management, 141, 65-81. https://doi.org/10.1016/j. ocecoaman.2017.03.005

Atkinson, S. C., Jupiter, S. D., Adams, V. M., Ingram, J. C., Narayan, S., Klein, C. J., \& Possingham, H. P. (2016). Prioritising mangrove ecosystem services results in spatially variable management priorities. PLOS ONE, 11, e0151992. https://doi.org/10.1371/journal.pone.0151992

Ball, I. R., Possingham, H. P., \& Watts, M. (2009). Marxan and relatives: Software for spatial conservation prioritisation. In A. Moilanen, K. A. Wilson, \& H. P. Possingham (Eds.), Spatial conservation prioritisation: Quantitative methods and computational tools (pp. 185-195). Oxford, UK: Oxford University Press.

Barbosa, A., Martín, B., Hermoso, V., Arévalo-Torres, J., Barbière, J., Martínez-López, J., ... Iglesias-Campos, A. (2019). An ecosystem-based management approach for the spatial planning of Green and Blue Infrastrucutre at the Intercontinental Biosphere Reserve of the Mediterranean: Andalusia (Spain) - Morocco. Science of the Total Environment, 652, 1463-1473.

Bennett, E. M., Cramer, W., Begossi, A., Cundill, G., Diaz, S., Egoh, B. N., ... Woodward, G. (2015). Linking biodiversity, ecosystem services, and human well-being: Three challenges for designing research for sustainability. Current Opinion in Environmental Sustainability, 14, 76-85. https://doi.org/10.1016/j.cosust.2015.03.007

Beyer, H. L., Dujardin, Y., Watts, M. E., \& Possingham, H. P. (2016). Solving conservation planning problems with integer linear programming. Ecological Modelling, 328, 14-22. https://doi.org/10.1016/j. ecolmodel.2016.02.005

Bini, L. M., Diniz, J. A. F., Rangel, T., Bastos, R. P., \& Pinto, M. P. (2006). Challenging Wallacean and Linnean shortfalls: Knowledge gradients and conservation planning in a biodiversity hotspot. Diversity and Distributions, 12, 475-482. https://doi.org/10.1111/ j.1366-9516.2006.00286.x

Bodin, Ö. (2017). Collaborative environmental governance: Achieving collective action in social-ecological systems. Science, 357, 659. https://doi.org/10.1126/science.aan1114
Booth, T. H., Nix, H. A., Busby, J. R., \& Hutchinson, M. F. (2014). BIOCLIM: The first species distribution modelling package, its early applications and relevance to most current MAXENT studies. Diversity and Distributions, 20, 1-9. https://doi.org/10.1111/ddi.12144

Bryan, B. A., Runting, R. K., Capon, T., Perring, M. P., Cunningham, S. C., Kragt, M. E., ... Wilson, K. A. (2016). Designer policy for carbon and biodiversity co-benefits under global change. Nature Climate Change, 6, 301-305. https://doi.org/10.1038/nclimate2874

Carwardine, J., Wilson, K. A., Watts, M., Etter, A., Klein, C. J., \& Possingham, H. P. (2008). Avoiding costly conservation mistakes: The importance of defining actions and costs in spatial priority setting. PLoS ONE, 3, e2586. https://doi.org/10.1371/journal.pone.0002586

Charniak, E. (1991). Bayesian networks without tears. Al Magazine, 12, 50-63.

Clark, J. S., Carpenter, S. R., Barber, M., Collins, S., Dobson, A., Foley, J. A., ... Wear, D. (2001). Ecological forecasts: An emerging imperative. Science, 293, 657-660. https://doi.org/10.1126/science.293.5530.657

Convention on Biological Diversity (CBD) (2010). Convention on Biolgoical Diversity's Strategic Plan for 2020. Montréal: CBD.

Council of the European Communities (1992). Council Directive 92/43/ EEC of 21 May 1992 on the conservation of natural habitats and of wild fauna and flora. Official Journal of the European Communities, L206, 7-50.

Council of the European Communities (2000). Directive 2000/60/EC of the European Parliament and the Council of 23rd October 2000 establishing a framework for community action in the field of water policy. Official Journal of the European Communities, L327, 1-72.

Council of the European Communities (2009). Directive 2009/147/EC of the European Parliament and of the Council of 30 November 2009 on the conservation of wild birds. Official Journal of the European Communities, L20, 7-25.

Domisch, S., Amatulli, G., \& Jetz, W. (2015). Near-global freshwater-specific environmental variables for biodiversity analyses in $1 \mathrm{~km}$ resolution. Scientific Data, 2, 150073. https://doi.org/10.1038/sdata.2015.73

Domisch, S., Langhans, S. D., Hermoso, V., Jähnig, S. C., Martínez-López, J., Balbi, S., ... van Hal, R. (2017). Guidance on methods and tools for the assessment of projected impacts of drivers of change on biodiversity, ecosystems functions and aquatic ecosystems service delivery; teaching modules for the individual modelling approaches: AQUACROSS Deliverable 7.1, European Union's Horizon 2020 Framework Programme for Research and Innovation Grant Agreement No. 642317.

Domisch, S., Kakouei, K., Martinez-López, J., Bagstad, K. J., Magrach, A. Balbi, S., ... Langhans, S. D. (2018). Social equity shapes zone-selection: Balancing aquatic biodiversity conservation and ecosystem services delivery in the transboundary Danube River Basin. Science of the Total Environment, https://doi.org/10.1016/j.scitotenv.2018.11.348

Eisenführ, F., Weber, M., \& Langer, T. (2010). Rational decision making. Berlin, Heidelberg: Springer-Verlag. https://doi.org/10.1007/978-3642-02851-9

Elith, J., \& Leathwick, J. R. (2009). Species Distribution Models: Ecological explanation and prediction across space and time. Annual Review of Ecology, Evolution, and Systematics, 40, 677-697. https://doi.org/ 10.1146/annurev.ecolsys.110308.120159

Ellison, A. M. (2004). Bayesian inference in ecology. Ecology Letters, 7 , 509-520. https://doi.org/10.1111/j.1461-0248.2004.00603.x

Ferraro, P. J. (2003). Assigning priority to environmental policy interventions in a heterogeneous world. Journal of Policy Analysis and Management, 22, 27-43. https://doi.org/10.1002/pam.10094

Fink, D., Hochachka, W. M., Zuckerberg, B., Winkler, D. W., Shaby, B., Munson, M. A., ... Kelling, S. (2010). Spatiotemporal exploratory models for broad-scale survey data. Ecological Applications, 20, 2131-2147. https://doi.org/10.1890/09-1340.1

Franklin, J., Wejnert, K. E., Hathaway, S. A., Rochester, C. J., \& Fisher, R. N. (2009). Effect of species rarity on the accuracy of species distribution models for reptiles and amphibians in southern California. Diversity 
and Distributions, 15, 167-177. https://doi.org/10.1111/j.14724642.2008.00536.x

Friedman, R. S., Law, E. A., Bennett, N. J., Ives, C. D., Thorn, J. P. R., \& Wilson, K. A. (2018). How just and just how? A systematic review of social equity in conservation research. Environmental Research Letters, 13. https://doi.org/10.1088/1748-9326/aabcde

Garcia-Prats, A., del Campo, A. D., \& Pulido-Velazquez, M. (2016). A hydroeconomic modeling framework for optimal integrated management of forest and water. Water Resources Research, 52, 8277-8294. https://doi.org/10.1002/2015WR018273

Gavish, Y., Marsh, C. J., Kuemmerlen, M., Stoll, S., Haase, P., \& Kunin, W. E. (2017). Accounting for biotic interactions through alpha-diversity constraints in stacked species distribution models. Methods in Ecology and Evolution, 8, 1092-1102. https://doi.org/10.1111/2041-210X.12731

Guisan, A., \& Zimmermann, N. E. (2000). Predictive habitat distribution models in ecology. Ecological Modelling, 135, 147-186. https://doi. org/10.1016/S0304-3800(00)00354-9

Harmel, R. D., Cooper, R. J., Slade, R. M., Haney, R. L., \& Arnold, J. G. (2006). Cumulative uncertainty in measured streamflow and water quality data for small watersheds. Transactions of the ASABE, 49, 689-701. https://doi.org/10.13031/2013.20488

Harrison, I. J., Green, P. A., Farrell, T. A., Juffe-Bignoli, D., Saenz, L., \& Vorosmarty, C. J. (2016). Protected areas and freshwater provisioning: A global assessment of freshwater provision, threats and management strategies to support human water security. Aquatic Conservation: Marine and Freshwater Ecosystems, 26, 103-120. https://doi.org/ 10.1002/aqc.2652

Hayes, M. A., Cryan, P. M., \& Wunder, M. B. (2015). Seasonally-dynamic presence-only species distribution models for a cryptic migratory bat impacted by wind energy development. PLoS ONE, 10, e0132599. https://doi.org/10.1371/journal.pone.0132599

Hermoso, V., Abell, R., Linke, S., \& Boon, P. (2016). The role of protected areas for freshwater biodiversity conservation: Challenges and opportunities in a rapidly changing world. Aquatic Conservation: Marine and Freshwater Ecosystems, 26, 3-11. https://doi.org/10.1002/aqc.2681

Hermoso, V., Cattarino, L., Kennard, M. J., Watts, M., \& Linke, S. (2015). Catchment zoning for freshwater conservation: Refining plans to enhance action on the ground. Journal of Applied Ecology, 52, 940-949. https://doi.org/10.1111/1365-2664.12454

Hermoso, V., Cattarino, L., Linke, S., \& Kennard, M. J. (2018). Catchment zoning to enhance co-benefits and minimise trade-offs between ecosystem services and freshwater biodiversity conservation. Aquatic Conservation: Marine and Freshwater Ecosystems, 28, 1004-1014. https://doi.org/10.1002/aqc.2891

Hermoso, V., Kennard, M. J., \& Linke, S. (2012). Integrating multidirectional connectivity requirements in systematic conservation planning for freshwater systems. Diversity and Distributions, 18, 448-458. https:// doi.org/10.1111/j.1472-4642.2011.00879.x

Hermoso, V., Linke, S., Prenda, J., \& Possingham, H. P. (2011). Addressing longitudinal connectivity in the systematic conservation planning of fresh waters. Freshwater Biology, 56, 57-70. https://doi.org/10.1111/ j.1365-2427.2009.02390.x

Juffe-Bignoli, D., Harrison, I., Butchart, S. H. M., Flitcroft, R., Hermoso, V., Jonas, H., ... Van Soesbergen, A. (2016). Achieving Aichi Biodiversity Target 11 to improve the performance of protected areas and conserve freshwater biodiversity. Aquatic Conservation: Marine and Freshwater Ecosystems, 26, 133-151. https://doi.org/10.1002/aqc.2638

Kail, J., Brabec, K., Poppe, M., \& Januschke, K. (2015). The effect of river restoration on fish, macroinvertebrates and aquatic macrophytes: A meta-analysis. Ecological Indicators, 58, 311-321. https://doi.org/ 10.1016/j.ecolind.2015.06.011

Kim, S., Robson, C., Zimmerman, T., Pierce, J., \& Haber, E. M. (2011). Creek watch: Pairing usefulness and usability for successful citizen science. Proceedings of the International Conference on Human Factors in Computing Systems, 2125-2134.
Klein, C. J., Ban, N. C., Halpern, B. S., Beger, M., Game, E. T., Grantham, H. S., ... Possingham, H. P. (2010). Prioritizing land and sea conservation investments to protect coral reefs. PLOS ONE, 5, e12431. https://doi. org/10.1371/journal.pone.0012431

Knutti, R. (2008). Should we believe model predictions of future climate change? Philosophical Transactions of the Royal Society A, 366 4647-4664. https://doi.org/10.1098/rsta.2008.0169

Kuemmerlen, M., Schmalz, B., Cai, Q. H., Haase, P., Fohrer, N., \& Jähnig, S. C. (2015). An attack on two fronts: Predicting how changes in land use and climate affect the distribution of stream macroinvertebrates. Freshwater Biology, 60, 1443-1458. https://doi.org/10.1111/fwb.12580

Langhans, S. D., Gessner, J., Hermoso, V., \& Wolter, C. (2016). Coupling systematic planning and expert judgement enhances the efficiency of river restoration. Science of the Total Environment, 560, 266-273. https://doi.org/10.1016/j.scitotenv.2016.03.232

Law, E. A., Bennett, N. J., Ives, C. D., Friedman, R., Davis, K. J., Archibald, C. \& Wilson, K. A. (2018). Equity trade-offs in conservation decision making. Conservation Biology, 32, 294-303. https://doi.org/10.1111/ cobi.13008

Lek, S., \& Guegan, J. F. (1999). Artificial neural networks as a tool in ecological modelling, an introduction. Ecological Modelling, 120, 65-73. https://doi.org/10.1016/S0304-3800(99)00092-7

Leonard, P. B., Baldwin, R. F., \& Hanks, R. D. (2017). Landscape-scale conservation design across biotic realms: Sequential integration of aquatic and terrestrial landscapes. Scientific Reports, 7, 14556. https://doi.org/10.1038/s41598-017-15304-w

Levin, N., Tulloch, A. I. T., Gordon, A., Mazor, T., Bunnefeld, N., \& Kark, S. (2013). Incorporating socioeconomic and political drivers of international collaboration into marine conservation planning. Bioscience, 63 , 547-563. https://doi.org/10.1525/bio.2013.63.7.8

Levin, P. S., Williams, G. D., Rehr, A., Norman, K. C., \& Harvey, C. J. (2015). Developing conservation targets in social-ecological systems. Ecology and Society, 20, 6. https://doi.org/10.5751/ES-07866-200406

Linke, S., Kennard, M. J., Hermoso, V., Olden, J. D., Stein, J., \& Pusey, B. J. (2012). Merging connectivity rules and large-scale condition assessment improves conservation adequacy in river systems. Journal of Applied Ecology, 49, 1036-1045. https://doi.org/10.1111/j.13652664.2012.02177.x

Long, R. D., Charles, A., \& Stephenson, R. L. (2015). Key principles of marine ecosystem-based management. Marine Policy, 57, 53-60. https://doi.org/10.1016/j.marpol.2015.01.013

Markovic, D., Carrizo, S., Freyhof, J., Cid, N., Lengyel, S., Scholz, M., ... Darwall, W. (2014). Europe's freshwater biodiversity under climate change: Distribution shifts and conservation needs. Diversity and Distributions, 20, 1097-1107. https://doi.org/10.1111/ddi.12232

Martínez-Fernández, J., Esteve-Selma, M. A., Martínez-Paz, J. M., Carreño, M. F., Martínez-López, J., Robledano, F., \& Farinós, P. (2014). Tradeoffs between biodiversity conservation and nutrients removal in wetlands of arid intensive agricultural basins: The Mar Menor case, Spain. In S. E. Jørgensen, N. B. Chang, \& F. L. Xu (Eds.), Advances in ecological modelling and ecological engineering applied on lakes and wetlands (pp. 275-310). USA: Elsevier. https:// doi.org/10.1016/B978-0-444-63249-4.00012-9

Martínez-López, J., Martínez-Fernández, J., Naimi, B., Carreño, M. F., \& Esteve, M. A. (2015). An open-source spatio-dynamic wetland model of plant community responses to hydrological pressures. Ecological Modelling, 306, 326-333. https://doi.org/10.1016/j.ecolmodel.2014.11.024

McDermott, M., Mahanty, S., \& Schreckenberg, K. (2013). Examining equity: A multidimensional framework for assessing equity in payments for ecosystem services. Environmental Science \& Policy, 33, 416-427. https://doi.org/10.1016/j.envsci.2012.10.006

Naidoo, R., \& Adamowicz, W. L. (2006). Modeling opportunity costs of conservation in transitional landscapes. Conservation Biology, 20, 490-500. https://doi.org/10.1111/j.1523-1739.2006.00304.x

Nassl, M., \& Löffler, J. (2015). Ecosystem services in coupled socialecological systems: Closing the cycle of service provision and societal 
feedback. Ambio, 44, 737-749. https://doi.org/10.1007/s13280-015 0651-y

Oteros-Rozas, E., Martin-Lopez, B., Daw, T. M., Bohensky, E. L., Butler, J. R. A., Hill, R., ... Vilardy, S. P. (2015). Participatory scenario planning in place-based social-ecological research: Insights and experiences from 23 case studies. Ecology and Society, 20, 32. https://doi.org/10.5751/ ES-07985-200432

Pecl, G. T., Araujo, M. B., Bell, J. D., Blanchard, J., Bonebrake, T. C., Chen, I. C., ... Williams, S. E. (2017). Biodiversity redistribution under climate change: Impacts on ecosystems and human well-being. Science, 355, eaai9214. https://doi.org/10.1126/science.aai9214

Perrings, C., Naeem, S., Ahrestani, F., Bunker, D. E., Burkill, P., Canziani, G., ... Weisser, W. (2010). Ecosystem services for 2020. Science, 330 323-324. https://doi.org/10.1126/science.1196431

Peterson, E. E., \& Hoef, J. M. V. (2010). A mixed-model moving-average approach to geostatistical modeling in stream networks. Ecology, 91, 644-651. https://doi.org/10.1890/08-1668.1

Pringle, C. M. (2001). Hydrologic connectivity and the management of biological reserves: A global perspective. Ecological Applications, 11, 981-998. https://doi.org/10.1890/1051-0761(2001)011[0981: HCATMO]2.0.CO;2

Qi, M., Sun, T., Xue, S. F., Yang, W., Shao, D. D., \& Martinez-Lopez, J. (2018). Competitive ability, stress tolerance and plant interactions along stress gradients. Ecology, 99, 848-857. https://doi.org/ 10.1002/ecy.2147

Reichert, P., \& Borsuk, M. E. (2005). Does high forecast uncertainty preclude effective decision support? Environmental Modelling \& Software, 20, 991-1001. https://doi.org/10.1016/j.envsoft.2004.10.005

Reichert, P., Langhans, S. D., Lienert, J., \& Schuwirth, N. (2015). The conceptual foundation of environmental decision support. Journal of Environmental Management, 154, 316-332. https://doi.org/10.1016/j. jenvman.2015.01.053

Revenga, C., Campbell, I., Abell, R., De Villiers, P., \& Bryer, M. (2005). Prospects for monitoring freshwater ecosystems towards the 2010 targets. Philosophical Transactions of the Royal Society, B: Biological Sciences, 360, 397-413. https://doi.org/10.1098/rstb.2004.1595

Ricaurte, L. F., Olaya-Rodriguez, M. H., Cepeda-Valencia, J., Lara, D., Arroyave-Suarez, J., Finlayson, C. M., \& Palomo, I. (2017). Future impacts of drivers of change on wetland ecosystem services in Colombia. Global Environmental Change - Human and Policy Dimensions, 44, 158-169. https://doi.org/10.1016/j.gloenvcha.2017.04.001

Rieman, B. E., Hessburg, P. F., Luce, C., \& Dare, M. R. (2010). Wildfire and management of forests and native fishes: Conflict or opportunity for convergent solutions? Bioscience, 60, 460-468. https://doi.org/ 10.1525/bio.2010.60.6.10

Rosa, I. M. D., Pereira, H. M., Ferrier, S., Alkemade, R., Acosta, L. A. Akcakaya, H. R., ... van Vuuren, D. (2017). Multiscale scenarios for nature futures. Nature Ecology \& Evolution, 1, 1416-1419. https://doi. org/10.1038/s41559-017-0273-9

Secretariat of the Convention on Biological Diversity (2014). Global Biodiversity Outlook 4. Montréal.

Sharp, R., Tallis, H. T., Ricketts, T., Guerry, A. D., Wood, S. A., ChaplinKramer, R., ... Douglass, J. (2018). InVEST +VERSION+ User's Guide. The Natural CapitalProject, Stanford University, University of Minnesota, The Nature Conservancy, and World Wildlife Fund.

Talley, J. L., Schneider, J., \& Lindquist, E. (2016). A simplified approach to stakeholder engagement in natural resource management: The FiveFeature Framework. Ecology and Society, 21, 38. https://doi.org/ 10.5751/ES-08830-210438

Tallis, H., \& Polasky, S. (2009). Mapping and valuing ecosystem services as an approach for conservation and natural-resource management. Annals of the New York Academy of Sciences, 1162, 265-283. https:// doi.org/10.1111/j.1749-6632.2009.04152.x
Tittensor, D. P., Walpole, M., Hill, S. L. L., Boyce, D. G., Britten, G. L., Burgess, N. D., ... Ye, Y. M. (2014). A mid-term analysis of progress toward international biodiversity targets. Science, 346, 241-244. https://doi.org/10.1126/science.1257484

Venohr, M., Langhans, S. D., Peters, O., Hoelker, F., Arlinghaus, R., Mitchell, L., \& Wolter, C. (2018). The underestimated dynamics and impacts of water-based recreational activities on freshwater ecosystems. Environmental Reviews, 26, 199-213. https://doi.org/10.1139/ er-2017-0024

Vermeiren, P., Munoz, C., Zimmer, M., \& Sheaves, M. (2016). Hierarchical toolbox: Ensuring scientific accuracy of citizen science for tropical coastal ecosystems. Ecological Indicators, 66, 242-250. https://doi. org/10.1016/j.ecolind.2016.01.031

Villa, F., Bagstad, K. J., Voigt, B., Johnson, G. W., Portela, R., Honzak, M., \& Batker, D. (2014). A methodology for adaptable and robust ecosystem services assessment. PLoS ONE, 9, e91001. https://doi.org/10.1371/ journal.pone.0091001

Villa, F., Portela, R., Onofri, L., Nunes, P. A. L. D., \& Lange, G. (2015). Assessing biophysical and economic dimensions of societal value: An example for water ecosystem services in Madagascar. In J. Martin-Ortega, R. C. Ferrier, I. J. Gordon, \& S. Khan (Eds.), Water ecosystem services: A global perspective (pp. 110-118). Cambridge, UK: Cambridge University Press. https://doi.org/10.1017/ CBO9781316178904.014

Vlachopoulou, M., Coughlin, D., Forrow, D., Kirk, S., Logan, P., \& Voulvoulis, N. (2014). The potential of using the Ecosystem Approach in the implementation of the EU Water Framework Directive. Science of the Total Environment, 470, 684-694. https://doi.org/10.1016/j. scitotenv.2013.09.072

Watts, M. E., Ball, I. R., Stewart, R. S., Klein, C. J., Wilson, K., Steinback, C., ... Possingham, H. P. (2009). Marxan with Zones: Software for optimal conservation based land- and sea-use zoning. Environmental Modelling \& Software, 24, 1513-1521. https://doi.org/10.1016/j. envsoft.2009.06.005

Waylen, K. A., Hastings, E. J., Banks, E. A., Holstead, K. L., Irvine, R. J., \& Blackstock, K. L. (2014). The need to disentangle key concepts from ecosystem-approach jargon. Conservation Biology, 28, 1215-1224. https://doi.org/10.1111/cobi.12331

Winking, C., Lorenz, A. W., Sures, B., \& Hering, D. (2016). Start at zero: Succession of benthic invertebrate assemblages in restored former sewage channels. Aquatic Sciences, 78, 683-694. https://doi.org/ 10.1007/s00027-015-0459-7

Wondolleck, J. M., \& Yaffee, S. L. (2017). Marine-ecosystem based management in practice: Different pathways, common lessons. Washington, Covelo, London: Island Press/Center for Resource Economics.

Woolsey, S., Capelli, F., Gonser, T., Hoehn, E., Hostmann, M., Junker, B., ... Peter, A. (2007). A strategy to assess river restoration success. Freshwater Biology, 52, 752-769. https://doi.org/10.1111/j.13652427.2007.01740.x

Zafra-Calvo, N., Pascual, U., Brockington, D., Coolsaet, B., CortesVazquez, J. A., Gross-Camp, N., ... Burgess, N. D. (2017). Towards an indicator system to assess equitable management in protected areas. Biological Conservation, 211, 134-141. https://doi.org/10.1016/j. biocon.2017.05.014

How to cite this article: Langhans SD, Domisch S, Balbi S, et al. Combining eight research areas to foster the uptake of ecosystem-based management in fresh waters. Aquatic Conserv: Mar Freshw Ecosyst. 2019;1-13. https://doi.org/ 10.1002/aqc.3012 